\title{
Oral health beliefs and behaviors of nurse and nurse practitioner students using the HU-DBI inventory: An opportunity for oral health vicarious learning
}

\author{
Kimberly K. Walker ${ }^{* 1,2}$, Richard D. Jackson ${ }^{3}$ \\ ${ }^{1}$ The Zimmerman School of Advertising and Mass Communications, University of South Florida, Tampa, FL, United States \\ ${ }^{2}$ School of Dentistry, Indiana University, Indianapolis, IN, United States \\ ${ }^{3}$ Department of Cariology, Operative Dentistry and Dental Public Health, Indiana University School of Dentistry, Indianapolis, \\ IN, United States
}

Received: January 9, 2017

Accepted: February 23, 2017

Online Published: March 6, 2017

DOI: $10.5430 /$ jnep.v7n8p19

URL: https://doi.org/10.5430/jnep.v7n8p19

\begin{abstract}
Background: Oral health access to care issues are resulting in curricular changes to train nursing students as oral health educators and providers. However, little data are available concerning their personal oral health beliefs/behaviors. The study purpose was to gather information from nurse and nurse practitioner students regarding their oral health beliefs and behaviors.

Methods: Using the Hiroshima University Dental Behavioural Inventory (HU-DBI), survey data were gathered from nurse and nurse practitioner students as well as dental hygiene students as controls concerning their oral health beliefs and behaviors.

Results: Mean HU-DBI scores were higher among nurse practitioner than nursing students, indicating more positive beliefs/behaviors, but both were lower than dental hygiene students. Both nurse and nurse practitioner students reported significantly fewer dental visits and some poorer hygiene practices than controls. Additionally, nursing students were more likely to believe that their teeth were worsening despite brushing.

Conclusions: Assessment of personal oral health beliefs/behaviors should occur early in nursing education with mentoring so that optimal modeling can positively impact patients' oral health. Oral health education opportunities within and among disciplines are discussed.
\end{abstract}

Key Words: Dental health, Nursing education, Nurse practitioner education, HU-DBI, Survey

\section{INTRODUCTION}

Dental caries is the most prevalent chronic health condition among children and adolescents, and it disproportionately affects other vulnerable populations, including the elderly and the economically disadvantaged. ${ }^{[1]}$ While efforts have been made to alleviate the impact of dental caries in these populations, significant barriers to oral care access remain, including manpower shortages and a maldistribution of practitioners. ${ }^{[2-8]}$

Recognizing the barriers, the Institute of Medicine (IOM) and the National Research Council formed the Committee on Oral Health Access to Services in 2009 to assess the delivery of oral health care to vulnerable and underserved populations in the U.S. ${ }^{[9]}$ The Committee envisioned an evidence-based

\footnotetext{
* Correspondence: Kimberly K. Walker; Email: walkerk1@usf.edu; Address: The Zimmerman School of Advertising and Mass Communications, University of South Florida, Tampa, FL, United States.
} 
oral healthcare system that allowed everyone quality access to oral health care. ${ }^{[9]}$

In 2011, the IOM released a follow-up report on the quality of oral health care in the nation, conveying the message that non-dental healthcare professionals have the potential to play a significant role in addressing the oral health needs and disparities in the U.S. ${ }^{[10]}$ They positioned non-dental healthcare professionals as essential to integrating oral health care into overall health care, especially for vulnerable populations.

With over 300 million licensed registered nurses in the U.S. workforce, including roughly 140,000 nurse practitioners, the profession is crucial to the delivery of oral health care. ${ }^{[11]}$ Nurse and nurse practitioners are often the first-point contacts with vast numbers of patients and can be influential role models for healthy behaviors. ${ }^{[12]}$ With enhanced professional education and training in oral health, they can greatly improve the access of oral health care for vulnerable populations. ${ }^{[10,13]}$ The purpose of this pilot study was to assess the oral health beliefs and behaviors of nurse and nurse practitioner students to aid their ability to educate and emulate positive oral health beliefs and behaviors for their patients.

\subsection{Literature review related to study purpose}

The nursing profession has an important new task in their expanding scope of practice: that of being an oral health educator and advocate. However, little data exist exploring their oral health beliefs and behaviors. The purpose of this literature review was to demonstrate the applied need for nurse and nurse practitioners to role model healthy oral health beliefs and behaviors, as well as to underscore the theoretical underpinnings of the modeling process. The primary study purpose, therefore, was to assess nurse and nurse practitioner students' oral health beliefs and behaviors with the Hiroshima University Dental Behavioural Inventory (HU-DBI). As far as we are aware, this is the first reported investigation to collect HU-DBI data from nurse practitioner students. A secondary purpose was to suggest arreas of educational opportunities for modeling best oral hygiene practices, within and among the health professions.

\subsection{Problem importance and related scholarship}

Poor oral health is a major public health concern. ${ }^{[14]}$ In 2000, the Surgeon General highlighted oral health as a major component of general health and well-being because it is essential to the general health of individuals and the population. ${ }^{[15]}$ Recent research indicates possible associations between chronic oral infections and diabetes, heart and lung disease, stroke, and low birthweight or premature births, in dicating that oral health ultimately supports and reflects the health of the entire body. ${ }^{[14]}$
Unfortunately, while much advancement in oral health has occurred, there are still many barriers that impact success. Wide and persistent disparities in oral health delivery exist, particularly among children, the elderly and those in rural communities. ${ }^{[15]}$ A prominent result of the IOM and other health institutions' call to expand access to oral care is that the nursing profession is being trained to assess oral health, apply fluoride varnish, and educate patients about the importance of oral health. ${ }^{[16-22]}$

However, oral health delivery has only recently become a priority for nurses in practice, and a continuing barrier to improving the oral health of the most vulnerable is inadequate education concerning basic oral health among non-dental healthcare professionals. ${ }^{[9,23]}$ To address the need, it is recommended to instill oral health as an important component of overall health early in a nurses' education because it can help inculcate oral health as a core principle of being healthy. The Committee on Oral Health Access to Services has recommended the development of a core set of oral health competencies and curricula for non-dental healthcare professionals to enhance their role in oral health promotion and disease prevention. ${ }^{[24]}$ In response, it is recommended that nursing programs need to prepare graduates with core competencies in providing oral health information. ${ }^{[24]}$

\subsubsection{Applied and theoretical importance of nurse and nurse practitioners' oral health beliefs and behav- iors}

Assessment of nurse and nurse practitioner students' oral health beliefs and behaviors is imperative because they can be role models for healthy behaviors. ${ }^{[13]}$ Social Cognitive Theory (SCT) provides a theoretical framework for understanding the process of positive role modeling that can be provided by nurse and nurse practitioners. SCT is a learning theory that proposes that individuals do not simply respond to environmental influences, rather they actively seek and interpret information. ${ }^{[25]}$ Self-efficacy is a core construct of SCT, as individuals need to feel confident that they can perform a behavior for which they have information. Two of the primary ways in which perceptions of efficacy are influenced is through vicarious experiences and verbal persuasive messages. ${ }^{[26,27]}$ Specifically, efficacy is strengthened when a person observes another individual successfully perform the behavior or when he/she receives positive verbal statements from a competent other like a teacher or mentor. ${ }^{[26,27]}$

In application, the nursing profession plays an integral role in promoting health and influencing lifestyle choices among patients. ${ }^{[28]}$ Viewing healthy oral health behaviors and hearing positive oral health attitudes spoken from nurse and nurse practitioners can build patients' self-efficacy to perform posi-

ISSN 1925-4040 E-ISSN 1925-4059 
tive oral health practices themselves. Research demonstrates that nurses who believe in health promotion and embrace healthy behaviors are more likely to be positive role models and teach healthy behaviors to their patients. ${ }^{[29]} \mathrm{A}$ large study of the relationship among nurses' exercise beliefs, personal exercise habits, and recommendations of exercise to patients, found that if nurses believe in exercise and do exercise, they are more likely to promote it to their patients. ${ }^{[29]}$ These findings support other research showing that the likelihood of healthcare providers counseling their patients about maintaining or improving their health is highly dependent upon the value they place upon maintaining their own health, emphasizing the need to enforce positive oral health beliefs and behaviors early in educational training. ${ }^{[30,31]}$

While the HU-DBI has been used to assess beliefs and behaviors of dental students, both within and outside of the United States, it has sparsely been used with those in non-dental professions.

\subsubsection{Summary}

The literature demonstrated a need and call for nurse and nurse practitioners to help provide access to oral health care, especially for vulnerable populations. It described the importance of modeling positive and correct oral health beliefs and behaviors for their patients. Findings of published studies show that while nurse and nurse practitioners who subscribe to their own healthy behaviors are more likely to counsel their patients about healthy behaviors, there is little data assessing their own oral health beliefs and behaviors.

\section{Methods}

\subsection{Purpose and research design}

The purpose of this cross sectional survey was to assess nurse and nurse practitioner students' oral health beliefs and behaviors with the HU-DBI. Additionally, dental hygiene students were assessed with the same instrument as controls. Assessment made comparisons among programs in individual belief and behavior survey items as well as in overall HU-DBI scores. Higher overall HU-DBI scores represent higher oral health beliefs and behaviors.

\subsection{Institutional review and ethical considerations}

The study was reviewed and approved by the Indiana University Institutional Review Board (IRB) for the Ethical Conduct of Research Committee. All participants were ensured anonymity. No identifying information that could directly link responses back to a particular student was collected. Written consent was obtained and participation was voluntary. The participants received no direct benefit. After the researchers collected surveys, the forms were stored in a locked cabinet in the principal investigator's office until re- viewed. Incomplete or erroneous forms (e.g. multiple responses to one question) were excluded from the data set. Once reviewed and tabulated, the data were transferred to electronic files for analyses.

\subsection{Setting and sample}

The survey was conducted in 2015 using a convenience sample of recruited students from the pre-licensure nursing (RN) and nurse practitioner (NP) programs of the Indiana University School of Nursing. Both the RN and NP students were beginning their final year of their prospective programs. For comparative purposes, dental hygiene (DH) students were also recruited from the Dental Hygiene (DH) program of the Indiana University School of Dentistry. They were either in the first or second year of their two-year pre-professional program.

Data collection took part during class time, upon instructors agreeing to allow participation. The survey was a one-time survey that took approximately 10 minutes to complete. The principal investigator introduced the study to all students in participating classes. All were invited to participate. Consent forms attached to surveys were passed out to all students in the class. Completed forms were obtained from 162 students, for an overall participation rate of 82 percent.

\subsection{Measures}

The HU-DBI consists of 20 statements about oral hygiene beliefs and behaviors that primarily fall into three categories: behaviors involving use of professional oral services (A), behaviors involving hygiene regimens (B), and oral health beliefs and esthetic concerns (C).

An example of a question in each category, in order, is "I put off going to the dentist until I have a toothache"; "I use a child-sized toothbrush"; and "I think that I cannot help having false teeth when I am old." The responses are dichotomous (agree-disagree). Twelve is the maximum score that may be attained, and this is based upon agreeing or disagreeing with specific statements within the 20 statements. Summation of the appropriate agree/disagree responses gives a quantitative estimate of oral health beliefs/behaviors, with a higher cumulative score being indicative of possessing more positive oral health beliefs and behaviors. The questions are provided in Table 3 along with an explanatory note concerning the scoring in the footnote. A more comprehensive description of the index can be found in Kawamura et al. ${ }^{[32-34]}$ The survey allows for a comparison of both overall HU-DBI scores and individual item ratings.

The HU-DBI is shown to have good test-retest reliability (0.73) over a 4-week period and has been translated into numerous languages to measure the beliefs and behaviors 
of a variety of healthcare students and professionals. ${ }^{[32-35]}$ It is also a culturally valid instrument. The HU-DBI was first used to measure Japanese dental students' beliefs and behaviors and has since been used to test beliefs and behaviors of dental students in other countries. In addition, we worked individually with a small pilot sample of our group (e.g. Americans) and asked them to "think aloud" as they engaged in responding to the items, asking how they interpreted and related the content to their personal experience. ${ }^{[36]}$

In addition to completing the HU-DBI, students provided demographic data, including their gender, race and age.

\section{Results}

\subsection{Data analysis}

All analyses were performed by one of the investigators using SPSS statistical software. Descriptive statistics were used on all variables. Chi-square tests were used to make comparisons of categorical data. ANOVA was used to calculate responses for differences in mean HU-DBI scores. Statistical significance was based on probability values of less than 0.05 .

\subsection{Descriptive summary of the sample}

Completed forms were obtained from 162 students: $51 \mathrm{RN}$, $46 \mathrm{NP}$ and $65 \mathrm{DH}$. The majority of the participants were female (88\%), self-identified as Caucasian and were between 23-27 years-of age. Table 1 shows the sample demographics.

\subsection{Overall HU-DBI scores}

Table 2 shows the mean HU-DBI scores by program and Table 3 presents the percentage distribution of the responses to the HU-DBI by program. An analysis of variance (ANOVA) yielded significant variation among conditions, $\mathrm{F}(2,161)=$ $21.00, p=.00$. A post hoc Tukey test showed that the mean HU-DBI score of the DH students was significantly higher than that of either the NP or the RN students.

Table 1. Overall sample demographics

\begin{tabular}{|c|c|c|c|c|c|c|c|c|}
\hline & \multicolumn{2}{|c|}{ Gender } & \multicolumn{3}{|l|}{ Race } & \multicolumn{3}{|c|}{ Age Range } \\
\hline & $\mathbf{N}$ & $\%$ & & $\mathbf{N}$ & $\%$ & & $\mathbf{N}$ & $\%$ \\
\hline Male & 17 & $10 \%$ & White & 146 & $91 \%$ & $18-22$ & 42 & $26 \%$ \\
\hline Female & 142 & $88 \%$ & Black & 5 & $3 \%$ & $23-27$ & 66 & $41 \%$ \\
\hline \multirow[t]{3}{*}{ Unknown } & 3 & $2 \%$ & Hispanic & 5 & $3 \%$ & 28-32 & 32 & $20 \%$ \\
\hline & & & Native American & 2 & $1 \%$ & $33-37$ & 15 & $9 \%$ \\
\hline & & & Multiple & 4 & $2 \%$ & $38+$ & 7 & $4 \%$ \\
\hline
\end{tabular}

Table 2. Mean HU-DBI scores by program

\begin{tabular}{lll}
\hline Program & N & Mean Score \\
\hline Dental Hygiene & $65^{*}$ & $8.25 \pm 1.08$ \\
Nurse Practitioner & 46 & $7.20 \pm 1.14$ \\
Nursing & 51 & $6.71 \pm 1.47$ \\
\hline
\end{tabular}

*Significant at the .05 level.

\subsection{Individual item scores within categories}

As seen in Table 3, significant differences in routine use of professional oral health services were found among the three programs. Of interest, 16 percent and 15 percent of the RN and NP students respectively responded that they would 'put off going to the dentist until they have a toothache', (Item $15 ; p=.004)$. In comparison to the $\mathrm{DH}$ students, $\mathrm{RN}$ and NP students were less likely to report that they had been told they were brushing their teeth well and more likely to report having never received oral hygiene instructions by a dental provider (Item 20, $p=.001$; Item 10, $p=.023$, respectively). $\mathrm{RN}$ students were significantly more likely to state that they did not worry much about visiting the dentist compared to
NP and DH students (Item 1, $p=.009$ ).

The frequency of responses to questions related to personal oral hygiene behaviors also differed significantly. RN students reported a significantly higher frequency of noticing dental plaque than did NP and DH students (Item 4, $p=.041$ ). $\mathrm{RN}$ and NP students were significantly less likely to respond that they brushed each tooth carefully (Item $9, p=.022$ ), that they used disclosing solution (Item 16, $p=.000$ ), or that they checked their teeth in the mirror after brushing (Item 12, $p=$ .01). Significantly more RN and NP students reported using a hard bristled toothbrush (Item 17, $p=.020$ ) than did DH students. No differences were found among groups in my gums tend to bleed when I brush and in using a child-size tooth brush (Item 2, 5, $p \geq .05$ ).

For beliefs, RN students were significantly more likely to believe their teeth were getting worse despite daily brushing (Item $8, p=.000$ ) than NP and DH students. While $28 \%$ of the DH students believed that they were able to clean their teeth well without using toothpaste, only a small percentage of RN and NP students held a similar belief (Item 11, $p=$ 
.000). Significantly more RN and NP students believed their toothbrushing was not effective unless they used "strong strokes" (Item 18, $p=.000$ ). RN students were significantly more likely to believe they worry about bad breath compared to the other students (Item 13, $p=.011$ ). There were no other differences in groups in esthetic beliefs, including worry about tooth color and gum color (Item 3, 7,p $\geq .05$ ). There were also no differences among groups in believing they would have false teeth when they were older, in believing they could prevent gum disease by toothbrushing alone or in believing they spend too much time brushing their teeth (Items 6, 14 and 19, $p>.05$ ).

Table 3. HU-DBI percentage of agreement responses by discipline

\begin{tabular}{|c|c|c|c|c|c|c|}
\hline \multirow{2}{*}{ No. Item Descriptions } & \multirow{2}{*}{\multicolumn{2}{|c|}{ Category }} & \multirow{2}{*}{$\begin{array}{l}\text { RN } \\
\%\end{array}$} & \multirow{2}{*}{$\begin{array}{l}\text { DH } \\
\%\end{array}$} & \multirow{2}{*}{$\begin{array}{l}\text { NP } \\
\%\end{array}$} & \multirow{2}{*}{$\chi^{2}$} \\
\hline & & & & & & \\
\hline 1. I don't worry much about visiting the dentist & A & & 41 & 22 & 15 & $9.58 * *$ \\
\hline 2. My gums tend to bleed when I brush my teeth & $\mathrm{D}$ & $\mathrm{B}$ & 9 & 2 & 11 & 5.28 \\
\hline 3. I worry about the colour of my teeth & & $\mathrm{C}$ & 84 & 78 & 85 & 0.98 \\
\hline 4. I have noticed some white, sticky deposits on my teeth & & B & 22 & 6 & 11 & $6.40^{*}$ \\
\hline 5. I use a child sized toothbrush & & $\mathrm{B}$ & 2 & 5 & 7 & 2.75 \\
\hline 6. I think that I cannot help having false teeth when I am old & $\mathrm{D}$ & $\mathrm{C}$ & 4 & 3 & 7 & 0.93 \\
\hline 7. I am bothered by the colour of my gums & & $\mathrm{C}$ & 6 & 5 & 11 & 1.71 \\
\hline 8. I think my teeth are getting worse despite my daily brushing & $\mathrm{D}$ & $\mathrm{C}$ & 29 & 3 & 9 & $18.60^{* * *}$ \\
\hline 9. I brush each of my teeth carefully & A & $\mathrm{B}$ & 75 & 91 & 72 & $7.70^{*}$ \\
\hline 10. I have never been professionally taught how to brush & $\mathrm{D}$ & A & 22 & 5 & 13 & $7.62 *$ \\
\hline 11. I think I can clean my teeth well without using toothpaste & A & $\mathrm{C}$ & 2 & 28 & 4 & $22.86^{* * *}$ \\
\hline 12. I often check my teeth in a mirror after brushing & A & $\mathrm{B}$ & 75 & 88 & 74 & $11.08 *$ \\
\hline 13. I worry about having bad breath & & $\mathrm{C}$ & 80 & 55 & 57 & $9.10^{*}$ \\
\hline 14. It is impossible to prevent gum disease with toothbrushing alone & $\mathrm{D}$ & $\mathrm{C}$ & 47 & 62 & 48 & 3.12 \\
\hline 15. I put off going to the dentist until I have a toothache & $\mathrm{D}$ & A & 16 & 0 & 15 & $11.08 * *$ \\
\hline 16. I have used a dye to see how clean my teeth are & A & B & 24 & 68 & 17 & $36.47 * * *$ \\
\hline 17. I use a toothbrush with hard bristles & & $\mathrm{B}$ & 16 & 2 & 13 & $7.90 *$ \\
\hline 18. I don't feel I've brushed well unless I brush with strong strokes & & $\mathrm{C}$ & 41 & 3 & 30 & $25.64 * * *$ \\
\hline 19. I feel I sometimes take too much time to brush my teeth & A & $\mathrm{C}$ & 20 & 23 & 9 & 3.94 \\
\hline 20. I have had my dentist tell me that I brush very well & & A & 73 & 95 & 72 & $13.92 * *$ \\
\hline
\end{tabular}

Note. Categories: Use of Services (A) Oral Hygiene Behaviors (B) Beliefs and Esthetic Concerns (C). $*=<.05$; ** $=<.01, * * *=<.001$; In the calculation of the HU-DBI: (A) = One point is given for each of these agree responses. (D) = One point is given for each of these disagree responses .

\section{Discussion}

As far as we are aware, this is the first reported investigation to collect HU-DBI data from nurse practitioner students. As nurse practitioners are being called upon to provide broadened access to oral care, the results are of interest. The data show the mean HU-DBI score of nurse practitioner students was higher than that of the nursing students, although not significantly, which indicates more overall positive oral health beliefs and behaviors of the nurse practitioner students. The reason for the more positive beliefs and behaviors may be due to the nurse practitioners' additional years of clinical training and education but also may include other factors that merit further investigation.

The most significant findings in this investigation were that the nursing students were more pessimistic about being able

Published by Sciedu Press to maintain their own oral health than were nurse practitioner students. Also, both stated they would delay seeking dental care unless they had an oral problem. Further investigations are warranted with other nurse and nurse practitioner students to see if similar results are obtained. The importance of these findings is that the pessimism expressed could result in a lowered perception of self-efficacy and an increased sense of fatalism. Fatalism is associated with the avoidance of preventive screenings and decreased utilization of preventive services. It is also a causative factor in poorer oral health outcomes. ${ }^{[37-39]}$ Additionally, some nurse and nurse practitioner students in our sample performed personal oral hygiene based upon outdated practices, including the use of hard bristled brushes and strong brushing strokes. These are not recommended because of the likelihood of damage to the 
gingival tissues and subsequent gingival recession.

Results of this investigation indicate that entering nurse and nurse practitioner students may be able to improve upon some of their oral health beliefs and behaviors in order to educate and model effective ones for their patients. Implications for the profession and recommendations follow.

\subsection{Implications for the profession}

The main study implication for the nursing profession is that if we are to expect nurse and nurse practitioners to positively influence the oral health of their patients and the larger community, then part of their early oral health education should include an assessment of their oral health beliefs and behaviors. The conceptual framework for this study is premised on research that demonstrates patients can learn healthy behaviors and beliefs through vicarious learning, whether through modeling and/or verbal word. Research shows that patients do model their health providers' behavior, and the modeling of oral health beliefs and behaviors helps to build patient self-efficacy. ${ }^{[40]}$ Self-efficacy in oral health is correlated with increased toothbrushing frequency and better oral health status among patients. ${ }^{[41]}$ The practice of healthy behaviors by healthcare providers is also a powerful predictor of counseling patients about these same behaviors. ${ }^{[42]}$ Furthermore, research shows a positive correlation between nurses receiving instruction for correct oral hygiene and maintenance of their patients' oral hygiene; ${ }^{[43]}$ Therefore, it is important to train nursing professionals who are well versed in the importance of oral health.

To do this, nursing faculty would optimally spend time early on assessing their students' personal oral health beliefs and practices and deconstructing less than optimal beliefs they may have concerning their oral health. Evidence-based materials, sufficient time and emphasis in the curriculum, and faculty who encourage the maintenance of good oral health are critical if students are to believe they have the ability to positively affect their own health and that of others. ${ }^{[44-46]}$ The following recommendations are made for educating nurse and nurse practitioner students about positive, evidenced-based oral health beliefs and behaviors from within and among health professions.

\subsection{Recommendations for improving oral health care in and among professions}

\subsubsection{Within nursing}

One way to assist students to develop an appreciation of the importance of oral self-care is to use an interactive model within an educational training framework. ${ }^{[47,48]}$ The priority of the model is to provide the student evidence-based health information that is relevant to their own oral health. Once issues are identified, the instructor and student identify measures that the student can then use to improve his/her health. Once the student is provided the means to address the issue, the student is given decisional control as to what measures to implement. The faculty member follows with attentive support and periodic re-assessments to ensure that health is maintained. The increased valuation they place on their oral health self-care can result in them being more likely to promote oral self-care in their patients. ${ }^{[49]}$ In addition to faculty mentors, didactic materials provided in the curriculum need to be updated to be aligned with current accepted oral health practices, and additional time must be devoted in the nursing curriculum in order to improve the oral health of the individual and the community. ${ }^{[24]}$

\subsubsection{Collaboration}

Another avenue for improving perceptions of oral health is to offer nurse and nurse practitioner students opportunities to train and interact with dental hygiene students on campuses where both programs co-exist. Inter-professional education programs such as that between New York University (NYU) College of Nursing and College of Dentistry are examples of innovative partnerships recently formed to encourage oralsystemic education and practice. ${ }^{[24]}$ These interactions could, over time, have a positive impact on nursing students' acceptance of being oral health promoters, and conversely, for dental hygiene students to be systemic health promoters. Such collaborative experiences correspond with callings for revamping educational programs to develop cohesive and inclusive healthcare teams and may lead to professional collaborations between dental hygienists and nurses in hospital emergency rooms and other healthcare settings. ${ }^{[50-52]}$

\subsection{Limitations}

This study had several limitations. The results were based on a one-time convenience sample of students in one geographic location. Although reflecting the traditional makeup of these professional programs, the sample was almost exclusively female and predominately Caucasian. In addition, the information was self-reported, and although the data were anonymous for the individual, the dental hygiene students may have felt that their self-reported behaviors should closely model standards of good oral health.

\subsection{Future directions}

There is still much work to be done to improve the oral health of our nation, especially with our most vulnerable populations. ${ }^{[10]}$ Improving the quality of oral health in America will require leadership and action from other health professions. ${ }^{[24]}$ With adequate education and training, the nursing profession has the potential to have a major impact on im- 
proving access and quality of oral health care. ${ }^{[24]}$

The next step in research is to collect more data from nurse and nurse practitioner programs around the nation with programs that have more diverse populations. While not significantly higher, the number of men entering the nursing profession is on the rise, ${ }^{[53]}$ and it would be informative to explore possible differences in responses in a more diverse

\section{REFERENCES}

[1] Benmamin RM. Oral health: the silent epidemic. Public Health Report. 2010 Mar-Apl; 125(2): 158-159. Available from: http: //www.jstor.org/stable/41434765

[2] American Academy of Pediatric Dentistry Originating Council. Policy on the dental home. American Academy of Pediatric Dentistry Reference Manual. 2015; 37(6): 24-25. Available from: http: //www. aapd.org/policies/

[3] Pediatrics. Maintaining and improving the oral health of young children. 2014 Dec; 122(6): 1387. Available from: http://pediatri cs . aappublications . org/content/134/6/1224

[4] Mertz E, O'Neil E. The growing challenge of providing oral health care services to all Americans. Health Affairs. 2002 Sept-Oct; 21(5): 65-77. https://doi.org/10.1377/hlthaff.21.5.65

[5] Discepolo K, Kaplan A. The Patient Protection and Affordable Care Act effects on dental care. The New York State Dental Journal. 2001 Aug-Sept; 77(5): 34-38.

[6] Garg S, Rubin T, Jasek J, et al. How willing are dentists to treat young children? A survey of dentists affiliated with Medicaid managed care in New York City, 2010. Journal of American Dental Association. 2013 Apr; 144(4): 416-425. http://dx.doi.org/10.14219/ja da.archive.2013.0135

[7] Casamassimo PS, Seale NS. Adequacy of patient pools to support predoctoral students' achievement of competence in pediatric dentistry in U.S. dental schools. Journal of Dental Education. 2015 June; 79(6): 644-652. PMid:26034028

[8] Institute of Medicine. Advancing oral health in America. Washington, DC: National Academies Press; 2011.

[9] Dolce MC, Aghazadeh-Sanai N, Mohammed S, et al. Integrating oral health into the interdisciplinary health sciences curriculum. Dental Clinics of North America. 2014 Oct; 58(4): 829-843. http://dx.doi.org/10.1016/j.cden.2014.07.002

[10] Institute of Medicine and National Research Council. Improving access to oral health care for vulnerable and underserved populations. Washington, DC: The National Academies Press. http: //dx.doi.org/10.1155/2012/567058

[11] Dolce MC. Integrating oral health into professional nursing practice: an interprofessional faculty tool kit. Journal of Professional Nursing. 2014 Jan-Feb; 30(1): 63-71. PMid:24503317 https: //doi.org/10.1016/j.profnurs. 2013.06.002

[12] Kieft RA, de Brouwer BB, Francke AL, et al. How nurses and their work environment affect patient experiences of the quality of care: a qualitative study. BMC Health Services Research. 2014 Jun; 14: 249. http://dx.doi.org/10.1186/1472-6963-14-249

[13] Rush KL, Rice M, Kee CC. Nurses as imperfect role models for health promotion. Western Journal of Nursing Research. 2005 Mar; 27(2): 166-183. PMid:15695573 https://doi.org/10.1177/01 93945904270082

Published by Sciedu Press sample. Continued and strategic sampling of nurse and nurse practitioner students' oral health beliefs and behaviors is needed to plan educational directives that can optimally aid their ability to model and educate patients about oral health initiatives.

\section{CONFlicts of InTEREST Disclosure}

The authors declare that there is no conflict of interest.
[14] Reigle JA, Holm K. Knowledge of oral health of nursing staff caring for disadvantaged older people. Journal of Nursing Education and Practice. 2016 Jan; 6(1): 31-38. http://dx.doi .org/10.5430/j nep.v6n1p31

[15] Patrick DL, Yin Lee RS, Nucci M, et al. Reducing oral health disparities: a focus on social and cultural determinants. BMC Oral Health. 2006 Jun; 6(1): S4. http://dx.doi.org/10.1186/147 2-6831-6-S1-S4

[16] Coleman P. Opportunities for nursing-dental collaboration:addressing oral health needs among the elderly. Nursing Outlook. 2005 Jan-Feb; 53(1): 33-39. http://dx.doi.org/10.1016/j. outlook. 2004. 06.008

[17] Jablonski R, Munro CL, Grap MJ, et al. Mouth care in nursing homes: knowledge, beliefs, and practices of nursing assistants. Geriatric Nursing. 2009 Mar-Apr; 30(2): 99-106. http://dx.doi.org $/ 10.1016 / j$.gerinurse .2008 .06 .010

[18] Hallas D, Fernandez J, Lim L, et al. Nursing strategies to reduce the incidence of early childhood caries in culturally diverse populations. Journal of Pediatric Nursing. 2011; 26(3): 248-256. http://dx.doi.org/10.1016/j.pedn.2009.07.010

[19] U.S. Department of Health and Human Services Health Resources and Services Administration. Integration of oral health and primary care practice report. 2014: 1-21. Available from: http://www.hrsa .gov/publichealth/clinical/oralhealth/primarycare/

[20] Golden A, Silverman M, Issenberg B. Addressing the shortage of geriatricians: what medical educators can learn from the nurse practitioner training model. Academic Medicine. 2015 Sept; 90(9): 12361240. http://dx.doi.org/10.1097/ACM. 0000000000000822

[21] Haber J, Hartnett E, Allen K, et al. Putting the mouth back in the head: HEENT to HEENOT. Public Health. 2015 March; 105(3): 437-441. http://dx.doi.org/10.2105/AJPH. 2014.302495

[22] Jablonski R, Mertz E, Featherstone JDB, et al. Maintaining oral health across the life span. The Nurse Practitioner. 2014 Jun; 39(6): 39-48. http://dx.doi.org/10.1097/01.NPR.000044 6872.76779 .56

[23] Clemmens DA, Kerr AR. Improving oral health in women: nurses' call to action. MCN American Journal of Maternal Child Nursing. 2008 Jan-Feb; 33(1): 10-14. http://dx.doi.org/10.1097/01. NMC. $0000305650.56000 . e 8$

[24] Dolce MC, Haber J, Shelley D. Oral health nursing education and practice program. Nursing Research and Practice. 2012; 2012(2012): 1-5. PMid:22685642 https://doi.org/10.1155/2012/149673

[25] Nevid JS. Psychology: concepts and applications (3rd ed.). Boston: Houghton Mifflin Company; 2009. http://dx.doi.org/10.10 80/08964289.2011.636770

[26] Bandura A. Social foundations of thought and action: A social cognitive theory. Englewood Cliffs, NJ: Prentice-Hall; 1986. 
[27] Bandura A. Self-efficacy and health behaviour. In A. Baum, S. Newman, J. Wienman, R. West, \& C. McManus (Eds.), Cambridge handbook of psychology, health and medicine. Cambridge: Cambridge University Press; 1997. 160-162 p.

[28] Deasy C, Coughlan B, Pironom J, et al. Predictors of health of preregistration nursing and midwifery students: findings from a cross sectional survey. Nurse Education Today. 2016 Jan; 36: 427-433. http://dx.doi.org/10.1016/j.nedt. 2015.09.010

[29] Esposito EM, Fitzpatrick, JJ. Registered nurses' beliefs of the benefits of exercise, their exercise behaviour and their patient teaching regarding exercise. International Journal of Nursing Practice. 2011 Aug; 17(4): 351-356. PMid:21781214 https ://doi.org/10.111 1/j.1440-172X.2011.01951.x

[30] Frank E, Carrera JS, Elon L, et al. Predictors of U.S. medical students' prevention counseling practices. Preventive Medicine. 2007 Jan; 44(1): 78-81. http://dx.doi.org/10.1016/j.ypmed. 200 6.07 .018

[31] Shahar DR, Henkin Y, Rozen GS, et al. Controlled intervention study of changing health-providers attitudes toward personal lifestyle habits and health promotion skills. Nutrition. 2009 May; 25(5): 532-539. http://dx.doi.org/10.1016/j.nut.2008.11.020

[32] Kawamura M, Honkala E, Widstrom E, et al. Cross-cultural differences of self-reported oral health behaviour in Japanese and Finnish dental students. International Dental Journal. 2000 Feb; 50(1): 46-50. PMid:10945180 https://doi.org/10.1111/j.1875-595X. 20 00.tb00546.x

[33] Kawamura M, Ikeda-Nakaoka Y, Sasahara H. An assessment of oral self-care level among Japanese dental hygiene students and general nursing students using the Hiroshima University - Dental Behavioural Inventory (HU-DBI): Surveys in 1990/1999. European Journal of Dental Education. 2000 May; 4: 82-88. PMid:11168468 https://doi.org/10.1034/j.1600-0579.2000.040206.x

[34] Kawamura M, Spadfora A, Kim KJ, et al. Comparison of United States and Korean dental hygiene students using the Hiroshima University- Dental Behavioral Invenoty (HU-DBI). International Dental Journal. 2002 Jun; 52(3): 156-162. PMid:12090266 https : //doi.org/10.1111/j.1875-595X.2002.tb00621.x

[35] Kawamura M, Wright FAC, Declerck D, et al. An exploratory study on cultural variations in oral health attitudes, behavior and values of freshman (first-year) dental students. International Dental Journal. 2005 Aug; 55 (4): 205-211. PMid:16167608 https: //doi.org/10.1111/j.1875-595X.2005.tb00317.x

[36] Yildiz S, Dogan B. Self reported dental health attitudes and behaviour of dental students in Turkey. European Journal of Dentistry. 2014 Jul; 5(3): 253-259.

[37] Lorig K, Holman H. Self-management education: history, definition, outcomes, and mechanisms. Annals of Behavioral Medicine. 2003 Aug; 26(1): 1-7. PMid:12867348 https ://doi.org/10.1207/S1 5324796ABM2601_01

[38] Levin L, Shenkman A. The relationship between dentalcaries status and oral health attitudes and behavior in young Israeli adults. Journal of Dental Education. 2004 Nov; 68(11): 1185-1194. PMid:15520238

[39] Jamieson L, Parker E, Roberts-Thomson K, et al. Self-efficacy and self-rated oral health among pregnant aboriginal Australian women BMC Oral Health. 2014 Apr; 14(2): 29-36. http://dx.doi.org /10.1186/1472-6831-14-29
[40] Bandura A. Health promotion from the perspective of social cognitive theory. Psychology and Health. 1998; 13: 623-649. https: //doi.org/10.1080/08870449808407422

[41] Anagnostopoulos F, Buchanan H, Frousiounioti S, et al. Self-efficacy and oral hygiene beliefs about toothbrushing in dental patients: a model-guided study. Behavioral Medicine. 2011 Oct; 37(4): 132-139. https://doi.org/10.1080/08964289.2011.636770

[42] Frank E. Physician health and patient care. Student JAMA. 2004; 291(5): 637.

[43] Ashkenazi M. The relationship between nurses' oral hygiene and mouth care of their patients. Special Care in Dentistry. 2013 Nov; 33(6): 280-285. http://dx.doi.org/10.1111/j.1754-4505. $2012.00306 . x$

[44] Shriver CB, Scott-Skiles A. Health habits of nursing versus nonnursing students: a longitudinal study. Journal of Nursing Education. 2000 Oct; 39(7): 308-314. PMid:11052653

[45] Forsell M, Kullberg E, Hoogstraate J, et al. An evidence-based oral hygiene education program for nursing staff. Nurse Education in Practice. $2011 \mathrm{Jul}$; 11(4): 256e-259e. http://dx.doi .org/10.10 16/j.nepr. 2010.11.017

[46] Chan JC, Chin LS. Oral health knowledge and psychological determinants of oral health behavior of nursing students. Journal of Health Psychology. 2015 July; 22(1): 1-10. http://dx . doi .org/10.11 $77 / 1359105315595122$

[47] Cox C. An interaction model of client health behavior: theoretical prescription for nursing. ANS Advances in Nursing Science. 1982 Oct; 5(1): 41-56. PMid:6817699 https : //doi .org/10.1097/00 012272-198210000-00007

[48] Matthews S, Secrest J, Muirhead L. The interaction model of client health behavior: a model for advanced practice nurses. Journal of the American Academy of Nurse Practitioners. 2008 Aug; 20(8): 415-422. http://dx.doi.org/10.1111/j.1745-7599. $2008.00343 . \mathrm{x}$

[49] Paulsson G, Soderfledt B, Nederfors T, et al. Nursing personnel's views on oral health from the health promotion perspective: a grounded theory analysis. Acta Odontologica Scandinavica. 2002 Feb; 60(1): 42-49. PMid:11902612 https ://doi.org/10.1080/ 000163502753471998

[50] Sargent J. Theories to aid understanding and implementation of interprofessional education. Journal of Continuing Education in the Health Professions. 2009 Summer; 29(3): 178-184. PMid:19728383 https://doi.org/10.1002/chp. 20033

[51] Duley SI, Fitzpatrick PG, Zornosa X, et al. A center for oral health promotion: establishing an inter-professional paradigm for dental hygiene, health care management and nursing education. Journal of Dental Hygiene. 2012 spring; 86(2): 63-70.

[52] Nathe C. Dental hygienists in emergency rooms. Registered Dental Hygienist (RDH). 2012. Available from: http: //www.rdhmag.com/articles/print/volume-33/is sue-1/coumns/dental-hygienists-in-emergency-rooms

[53] Zamanzadeh V, Valizadeh L, Negarandeh R, et al. Factors influencing men entering the nursing profession, and understanding the challenges faced by them: Iranian and developed countries' perspectives. Nursing and Midwifery Studies. 2013 Dec; 2(4): 49-56. PMid:25414879 